\title{
Upregulation of GABA Neurotransmission Suppresses Hippocampal Excitability and Prevents Long-Term Potentiation in Transgenic Superoxide Dismutase-Overexpressing Mice
}

\author{
Y. Levkovitz, ${ }^{1}$ E. Avignone, ${ }^{1}$ Y. Groner, ${ }^{2}$ and M. Segal ${ }^{1}$ \\ Departments of ${ }^{1}$ Neurobiology and ${ }^{2}$ Molecular Genetics, The Weizmann Institute, Rehovot 76100, Israel
}

\begin{abstract}
$\mathrm{Cu} / \mathrm{Zn}$ superoxide dismutase (SOD-1) is a key enzyme in oxygen metabolism in the brain. Overexpression of SOD-1 in transgenic $(\mathrm{Tg})$ mice has been used to study the functional roles of this enzyme in oxidative stress, lipid peroxidation, and neurotoxicity. We found that Tg-SOD-1 mice are strikingly less sensitive to kainic acid-induced behavioral seizures than control mice. Furthermore, the hippocampus of Tg-SOD-1 mice was far less sensitive to local application of bicuculline, a GABA-A antagonist, than the hippocampus of control mice. GABAergic functions, expressed in extracellular paired-pulse depression,
\end{abstract}

Oxidative stress constitutes a major cause of neurodegeneration in the brain. Reactive oxygen species enhance lipid peroxidation and retard the ability of cells to handle calcium loads, leading to apoptotic cell death (Choi, 1994). The enzyme superoxide dismutase (SOD-1) that catalyzes the conversion of superoxide radicals $\left(\mathrm{O}_{2}^{*}\right)$ into $\mathrm{H}_{2} \mathrm{O}_{2}$, plays an important role in the metabolism of oxygen-free radicals (OFR). The intracellularly generated $\mathrm{H}_{2} \mathrm{O}_{2}$ is further metabolized to water by glutathione peroxidase. However, when the activity of SOD-1 is increased without a concomitant increase in glutathione peroxidase, $\mathrm{H}_{2} \mathrm{O}_{2}$ accumulates, and its reaction with transition metals (the Fenton's reaction) is facilitated (Halliwell, 1992). The product of Fenton's reaction is hydroxyl radical $(* \mathrm{OH})$, the most reactive and noxious OFR species. There is evidence that elevated activity of SOD-1 can be deleterious (Elroy-Stein et al., 1986; Avraham et al., 1988; Elroy-Stein and Groner, 1988; Norris and Hornsby, 1990; Amstad et al., 1991; Bar-Peled et al., 1996; Peled-Kamar et al., 1997; Gahtan et al., 1998), i.e., an increase in SOD-1 activity causes oxidative injury-mediated phenotypic aberrations. Using model systems of transgenic cells and mice, it was found that stably transfected cells overexpressing SOD-1 showed substantially increased lipid peroxidation associated with a specific lesion affecting the chromaffin granule's proton pump (Elroy-Stein and Groner, 1988). A similar defect was also identified in transgenic SOD-1 mice (Tg-SOD) (Avraham et al., 1988; Peled-Kamar et al., 1997), and cultured neurons taken from these mice exhibit higher susceptibility to kainic acid (KA)-induced apoptosis (Bar-Peled et al., 1996). Other studies report that Tg-SOD-1 animals have

\footnotetext{
Received Aug. 10, 1999; revised Sept. 24, 1999; accepted Sept. 28, 1999.

This work was supported by grants from the Biomedicine and Health research program BIOMED II, number PL963039 of the Commission of the European Community, the Israeli Ministry of Science, and the Shapell family foundation at the Weizmann Institute and by the Edward Kass Award to Y.L.

Correspondence should be addressed to M. Segal, Department of Neurobiology, The Weizmann Institute, Rehovot 76100, Israel. E-mail: jnsegal@weizmann. weizmann.ac.il

Copyright (C) 1999 Society for Neuroscience 0270-6474/99/1910977-08\$05.00/0
}

and in IPSCs recorded in dentate granular cells were enhanced in Tg-SOD-1 mice. Finally, long-term potentiation (LTP), not found in the dentate gyrus of Tg-SOD-1 mice, could be restored by local blockade of inhibition and could be blocked in control mice by injection of diazepam, which amplifies inhibition. These results indicate that constitutive elevation of SOD-1 activity exerts a major effect on neuronal excitability in the hippocampus, which, in turn, controls hippocampal ability to express LTP.

Key words: transgenic SOD-1 mice; LTP; seizure; hippocampus; IPSCs; perforant path either lower (Chan et al., 1990) or similar (Kondo et al., 1997) sensitivity to neurotoxic insults as compared to nontransgenic control mice.

Here we report that two independently derived lines of $\mathrm{Tg}$ SOD mice are strikingly more resistant than control mice to KA-induced seizures (Ben-Ari, 1985). This reduced sensitivity to KA is associated with an apparent constitutively enhanced GABAergic neurotransmission in the brain of the Tg-SOD mice, leading to reduction in excitability and expression of neuronal plasticity.

\section{MATERIALS AND METHODS}

Transgenic mice. Transgenic mice harboring the human SOD-1 gene were produced by microinjecting fertilized eggs with a linear $14.5 \mathrm{~kb}$ fragment of human genomic DNA containing the entire CuZnSOD gene, including its regulatory sequences, as previously described (Epstein et al., 1987; Avraham et al., 1988; Bar-Peled et al., 1996; Gahtan et al., 1998). All experiments were performed with adult males of two transgenic lines (Tg-51 and Tg-69) and age and strain-matched control mice. The two independently derived lines contain four or five copies of the human SOD-1 gene in their genome and overexpressed the transgene as an active enzyme (Epstein et al., 1987; Gahtan et al., 1998).

Kainic acid-induced seizure. Mice were injected intraperitoneally with $22.5,27.5$, or $35 \mathrm{mg} / \mathrm{kg}$ kainic acid. The mice were then placed in a $1.2 \mathrm{~m}$ diameter circular arena. Their behavior was scored every 5 min for 65 min into five categories, as follows (Yang et al., 1997): (1) arrest of motion; (2) myoclonic jerks of the head and neck, with brief twitching movements; (3) unilateral clonic activity; (4) bilateral forelimb tonic and clonic activity; and (5) generalized tonic-clonic activity with loss of postural tone leading to eventual death after continuous convulsions.

Electrophysiology: in vivo. Mice were anesthetized with urethane $(21 \%$ solution; $1.2 \mathrm{gm} / \mathrm{kg}$, i.p.) and placed in a stereotaxic apparatus. A bipolar, $125 \mu \mathrm{m}$ concentric stimulating electrode was placed in the perforant path (PP) (coordinates, $0.5 \mathrm{~mm}$ anterior to lambda, $2.5 \mathrm{~mm}$ lateral to the midline; depth, 1.7-2.0 mm), and a glass pipette (diameter of 2-3 $\mu \mathrm{m}$ ) containing $2 \mathrm{M} \mathrm{NaCl}$ was moved into the dentate gyrus of the dorsal hippocampus using a hydraulic microdrive (coordinates, $2.0 \mathrm{~mm}$ posterior to bregma, 1.0 lateral to the midline; depth, 1.8-2.2 mm). Electrode positions were optimized to record maximal population spike (PS) in response to $100 \mu \mathrm{sec}$ pulse stimulation of the medial PP. When a bicuculline-filled pipette was used, it was introduced into the same 
location as the previous recording pipette. Bicuculline was prepared in 2 $\mathrm{M} \mathrm{NaCl}$ at $1-10 \mathrm{~mm}$ concentration from frozen stocks. The location of the drug pipette was verified by the production of the same EPSP to the same stimulation intensity, as detailed elsewhere (Levkovitz and Segal, 1997). Evoked responses were amplified, filtered at $1 \mathrm{~Hz}-1 \mathrm{kHz}$, and stored for later analysis. A twin pulse PP stimulus was delivered at three interpulse intervals $(15,30$, and $60 \mathrm{msec})$, and averages of five successive responses to a given intensity applied at a rate of $0.5 \mathrm{~Hz}$ were constructed. Paired-pulse responses were quantified as the magnitude of the second over the first PS or the slope of the second EPSP over the first one. After electrode insertion, recording was allowed to stabilize for $15 \mathrm{~min}$. Inputoutput relations and paired-pulse responses were obtained thereafter, before application of a tetanic stimulation. The LTP-inducing stimulation was at $50 \%$ of the level that evoked a maximal asymptotic spike amplitude. LTP was induced with five trains of eight $0.4 \mathrm{msec}, 400 \mathrm{~Hz}$ pulses spaced $10 \mathrm{sec}$ apart. LTP in each experiment was assessed as the change in response measured 35-40 min after the tetanus and expressed as a percentage of the mean of the 20 responses obtained within $10 \mathrm{~min}$ before the tetanus. Paired $t$ tests or ANOVA tests were used for statistical comparisons when applicable.

Electrophysiology: brain slices. Hippocampal slices were obtained from 2- to 3-month-old mice. Briefly, a mouse was anesthetized with ketamine, decapitated, and its brain was quickly removed and immersed in cold artificial CSF (ACSF; composition in mM: $\mathrm{NaCl} 124, \mathrm{NaHCO}_{3} 26, \mathrm{KCl}$ $4, \mathrm{NaH}_{2} \mathrm{PO}_{4} 1.25, \mathrm{CaCl}_{2} 2, \mathrm{MgSO}_{4} 2$, and glucose 10 ). Osmolarity was adjusted with sucrose to $310 \mathrm{mOsm}$, and $\mathrm{pH}$ was 7.4. The two hemispheres were separated, and $400-\mu \mathrm{m}$-thick sagittal slices were cut with a vibratome in ice-cold ACSF. Slices were allowed to recover for at least 1 $\mathrm{hr}$ at room temperature and then transferred into the recording chamber where they were superfused with oxygenated ACSF at $33-34^{\circ} \mathrm{C}$ at a constant rate of $3 \mathrm{ml} / \mathrm{min}$. To record GABAergic activity, $20 \mu \mathrm{M}$ APV and $10 \mu \mathrm{M}$ DNQX were added to the ACSF. When miniature IPSCs (mIPSCs) were recorded, TTX $(1 \mu \mathrm{M})$ was also included in the perfusion medium.

Cells in the granular layer were identified using a Zeiss Axioscope microscope equipped with Nomarski optics, a water-immersion lens, and an infrared camera. Patch pipettes contained (in mM): $\mathrm{CsCl} 140, \mathrm{Na}_{2}-$ phosphocreatine 10, MgATP 2, GTP-Na 0.3, HEPES 10, and $\mathrm{NaCl} 1, \mathrm{pH}$ 7.3. Osmolarity was adjusted with sucrose to $300 \mathrm{mOsm}$. The lidocaine derivative, QX-314 (5 mM) was added to the intracellular solution to block action potentials in the recorded cell so as not to interfere with recording of spontaneous synaptic currents. Signals were amplified with Axopatch-200A amplifier, filtered at $10 \mathrm{kHz}$, and stored in an IBM personal computer using Axon Instruments (Foster City, CA) software. Cells were clamped at a potential ranging from -65 to $-70 \mathrm{mV}$, and inward GABA-mediated synaptic currents were recorded. Mini analysis software was used to calculate the averages of area, amplitude, rise time, and decay time of the events. Only events distanced at least $20 \mathrm{msec}$ apart were examined. Because the distributions of these parameters were not Gaussian, the medians were taken as representative values for each cell. Data are expressed as mean \pm SE. To compare the results between the two groups of cells, unpaired Student's $t$ tests were applied, and $p=0.05$ was the significance level.

\section{RESULTS}

\section{KA-induced behavioral seizure}

An injection of $27.5 \mathrm{mg} / \mathrm{kg}$ of KA induced behavioral seizures of progressive severity in both control groups of mice $(n=6$ and 11 for control mice of line numbers 51 and 69, respectively) (Fig. 1). Mice first exhibited "staring" spells with abnormal body posture, progressed to head nodding, forepaw tremor, rearing, loss of postural control, and eventually continuous convulsions. In contrast, Tg-SOD mice (both 51 and 69 lines; $n=6$ and 11, respectively) showed only mild symptoms, consisting mainly of staring spells and occasional myoclonic tremors, and recovered rapidly. At a higher dose of KA ( $35 \mathrm{mg} / \mathrm{kg})$, six of the seven control mice died after continuous tonic-clonic convulsions, whereas all seven Tg-SOD mice survived the treatment. Further experiments showed no differences between lines 51 and 69, and their results were therefore pooled.

The reduced susceptibility of $\mathrm{Tg}-\mathrm{SOD}$ mice to KA may reflect

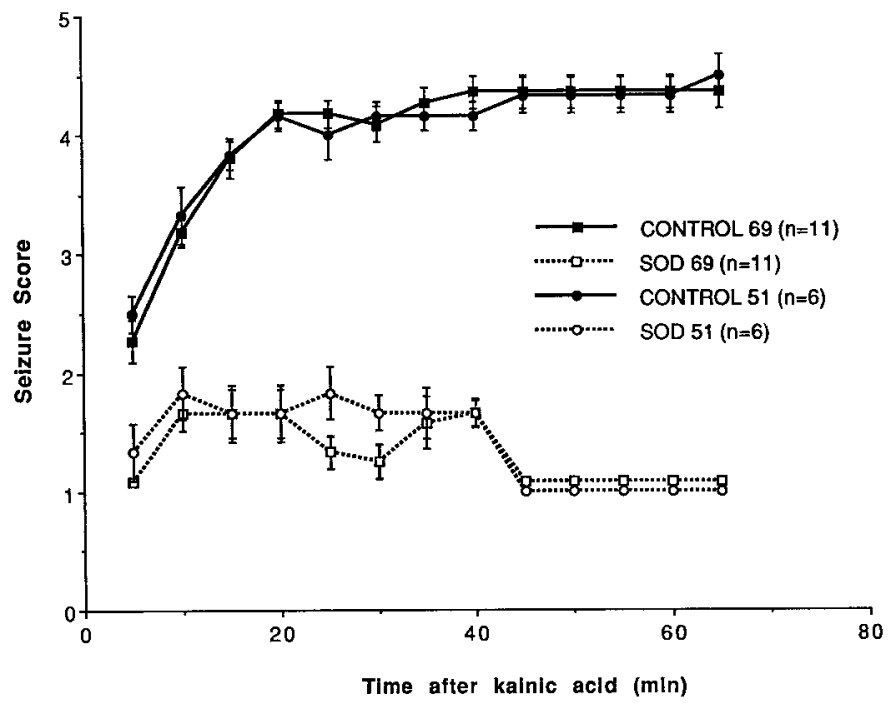

Figure 1. Behavioral seizures in response to kainic acid in control and Tg-SOD mice. KA (27.5 mg/kg, i.p.) was injected to the mouse, and its behavior was monitored and scored on a scale of $1-5$ every 5 min. The results of two lines, SOD 51 and SOD 69, and their corresponding controls are presented separately. Most of the control mice died eventually, whereas all of the SOD mice survived the test.

an altered peripheral or central metabolism or mobility of the drug or a genuine difference in the epileptogenic properties of the drug in the brain. We examined these possibilities by recording the effects of KA in the anesthetized mouse brain, as follows.

\section{In vivo recording of epileptic activity}

An intraperitoneal injection of KA at a dose of $10 \mathrm{mg} / \mathrm{kg}$ caused epileptic activity in the dentate granular layer in five of six anesthetized control mice, but in none of six Tg-SOD mice (Fig. 2). A dose of $20 \mathrm{mg} / \mathrm{kg}$ caused epileptic activity in the dentate gyrus of all six control mice, but only in one of six Tg-SOD mice studied. This abnormal electrical activity started within 5-10 min after the injection and continued for as long as recording was made (up to $1 \mathrm{hr}$ ). We then resorted to a more direct way to test if the hippocampus itself is less susceptible to epileptic seizure, and applied an epileptogenic stimulus, the GABA-A antagonist bicuculline, directly through the recording pipette (Steward et al., 1990; Levkovitz and Segal, 1997). We found epileptic activity in all six control mice but only in one of six Tg-SOD mice recorded with a pipette containing $5 \mathrm{~mm}$ bicuculline. A lower concentration of the drug $(1 \mathrm{~mm})$ did not produce an epileptic response (but see below) (Fig. 2). These results indicate that the Tg-SOD mice are far more resistant to epileptic activity than control mice.

We then focused on the analysis of possible causes for the striking difference between control and Tg-SOD mice. To this end, we recorded responses of the dentate gyrus to perforant path stimulation. The input-output relationship was similar in control $(n=20)$ and Tg-SOD $(n=20)$ mice. Both the population EPSPs and the PSs maintained the same relationship to stimulation intensity (Fig. 3). At stimulation intensities that yielded $50 \%$ of the maximal responses, chosen as baseline, the EPSP slopes and PSs were for controls $2.4 \pm 0.5 \mathrm{~V} / \mathrm{sec}$ and $4.0 \pm 0.6 \mathrm{mV}$, respectively. For Tg-SOD (line 69) $2.0 \pm 0.6 \mathrm{~V} / \mathrm{sec}$ and $5.3 \pm 0.5 \mathrm{mV}$, respectively, and for Tg-SOD (line 51) $2.1 \pm 0.3 \mathrm{~V} / \mathrm{sec}$ and $5.0 \pm$ $0.8 \mathrm{mV}$, respectively. There were no differences in either of the two parameters between the three groups. This indicates that Tg-SOD mice are not different from controls in the excitatory 

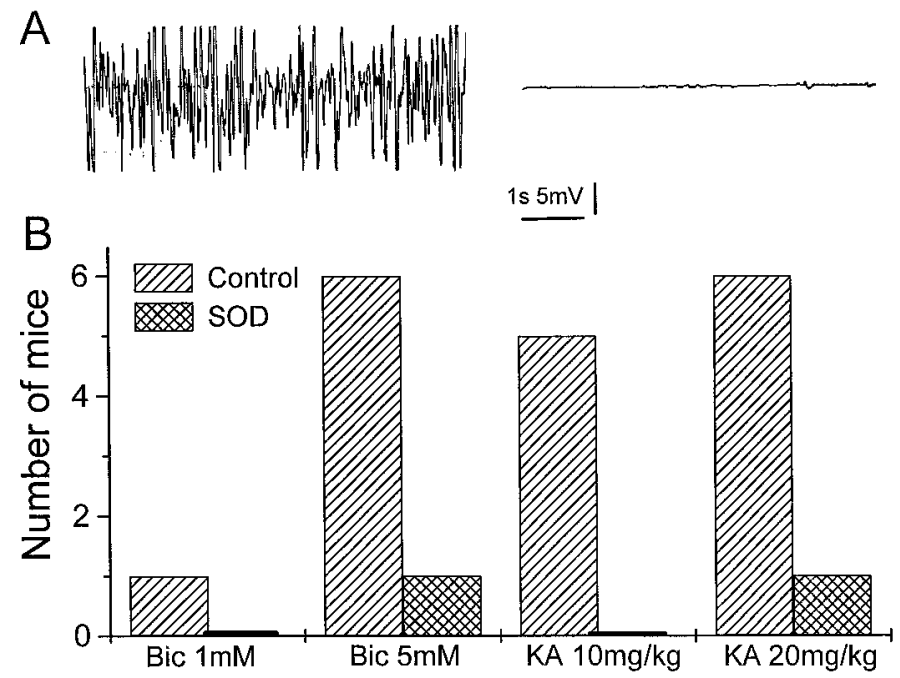

Figure 2. Electrographic epilepsy in anesthetized mice. $A$, Illustration of seizure activity in the control mouse (left) and the lack of such activity in the Tg-SOD mouse, after an intraperitoneal injection of $20 \mathrm{mg} / \mathrm{kg}$ of KA. The identification of epileptic activity was clear-cut, and the mice were scored as having or not having seizures within 10-20 min after the injection. $B$, Summary of results for the presence of seizure activity in groups of six mice each after (from left to right) local application of 1 or $5 \mathrm{~mm}$ bicuculline and peripheral application of 10 and $20 \mathrm{mg} / \mathrm{kg} \mathrm{KA}$.

tone of this main afferent pathway or in the ability to discharge action potentials in response to stimulation.

\section{Local modulation of inhibitory synapses}

To assess the role of SOD-1 in inhibitory circuits of the hippocampus, lower concentrations of bicuculline were applied through the recording pipette, and the changes in population EPSP and spike were measured. Replacement of the saline recording pipette with one containing $1 \mathrm{~mm}$ bicuculline caused a significant increase in population spike response to PP stimulation in the control mice $(n=6$; at $2 \mathrm{~V}$ stimulation with a saline pipette, the increase in PS from baseline was $62.2 \pm 8.12 \%$; with a bicuculline pipette, $117.5 \pm 10.83 \%$; $t$ test; $p<0.006$ ) but not in the Tg-SOD mice ( $n=6$; at $2 \mathrm{~V}$ stimulation, bicuculline increase above baseline amounted only to $61.3 \pm 12.2 \%$ ) (Fig. $4 A, B)$. The primary effect of bicuculline was on the size of the population spike. The drug had no effect on the slope of the EPSP, suggesting an increase in the excitability of granular cells caused by a reduction in feedforward inhibition rather than a change in transmission at the perforant path synapse. (Fig. 4C). Higher concentration $(5 \mathrm{~mm})$ of bicuculline in the pipette caused epileptic activity in the control (see above) and a significant increase (but with no epileptic activity) in population spike response to PP stimulation in the Tg-SOD mice (Fig. $4 B)(n=6$ mice; at $2 \mathrm{~V}$ stimulation, saline pipette, $57.05 \pm 6.16 \%$; bicuculline pipette, $98.33 \pm 13.12 \% ; t$ test; $p<0.001)$.

\section{Paired-pulse inhibition}

The possibility that SOD-1 affects local GABAergic interneurons was tested more directly by examining the responses to a pairedpulse stimulation applied to the perforant path (Sloviter, 1991). In control mice, the response to the second of two stimuli was reduced by $50 \%$ when it followed the first one by $15 \mathrm{msec}$ (Fig. 5). The suppression was reversed to facilitation with a $60 \mathrm{msec}$ interstimulus interval. In contrast, the response to a second stimulus was totally suppressed if it followed a priming stimulus by 15
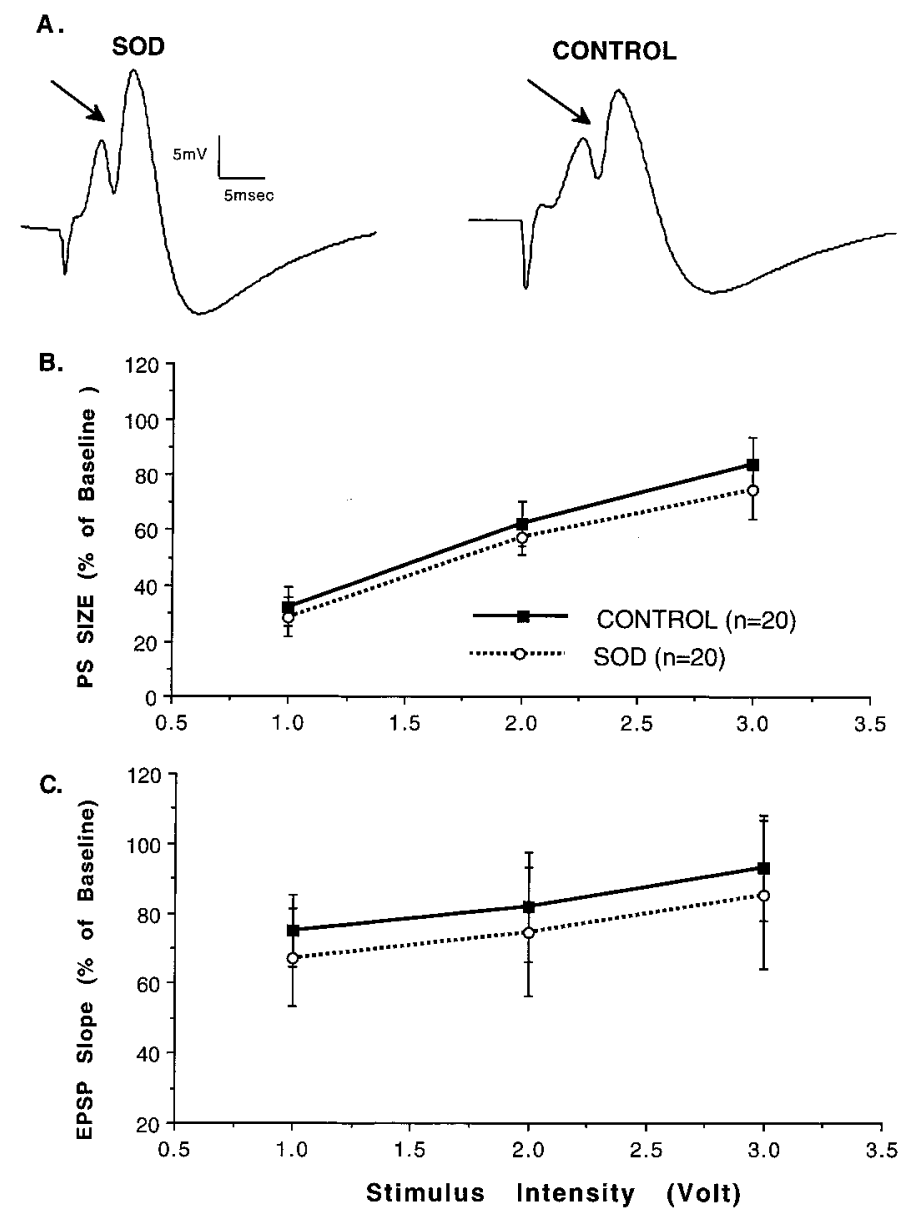

Figure 3. Reactivity to afferent stimulation is the same in control and $\mathrm{Tg}$-SOD mice. $A$, Sample illustrations of population responses recorded in the granular layer to stimulation of the perforant path. Stimulus artifact, downward deflection. Population spikes are marked with an arrowhead. $B$, $C$, Input-output relations, depicting the changes in population spike $(B)$ and EPSP slope $(C)$ as a function of changes in stimulation intensity, are the same in the two groups of mice. Results of 20 mice in each group, including mice of the two lines, are summarized herein.

or $30 \mathrm{msec}$ in the Tg-SOD mice (Fig. 5). This suppression was blocked at the longer interpulse interval $(60 \mathrm{msec})$, but was not converted to facilitation. The paired-pulse suppression at $15 \mathrm{msec}$ was not significantly changed after locally applied bicuculline via the recording pipette or after an intraperitoneal injection of KA $(10 \mathrm{mg} / \mathrm{kg})$. Only at $30 \mathrm{msec}$ interpulse interval, KA injected intraperitoneally caused significant increase in the magnitude of the second pulse $(n=6$; Tg-SOD; PS2/PS1 $=0.05 \pm 0.08$; after $\mathrm{KA}, \mathrm{PS} 2 / \mathrm{PS} 1=0.41 \pm 0.14 ; t$ test; $p<0.005)$.

In contrast, bicuculline reduced paired-pulse inhibition at 15 and $30 \mathrm{msec}$ interpulse intervals (Fig. $5 B$ ) in the control mice $[n=$ 6 ; control pipette, interpulse interval $(\mathrm{IPI})=30, \mathrm{PS} 2 / \mathrm{PS} 1=$ $1.11 \pm 0.19, \mathrm{IPI}=60, \mathrm{PS} 2 / \mathrm{PS} 1=1.9 \pm 0.32$; bicuculline pipette, $\mathrm{IPI}=30, \mathrm{PS} 2 / \mathrm{PS} 1=1.48 \pm 0.11, \mathrm{IPI}=60, \mathrm{PS} 2 / \mathrm{PS} 1=2.35 \pm$ 0.47 ; $t$ test; $p<0.004, p<0.0046$ for IPI $=30$ and IPI $=60$, respectively]. These experiments indicate that the Tg-SOD mice have a more profound inhibitory control in the dentate gyrus, which is less sensitive to bicuculline, and which may underlie the higher resistance to seizure in the Tg-SOD mice. The cellular mechanisms responsible for this functional difference in GABA inhibition were studied in the in vitro slice preparation. 
A.
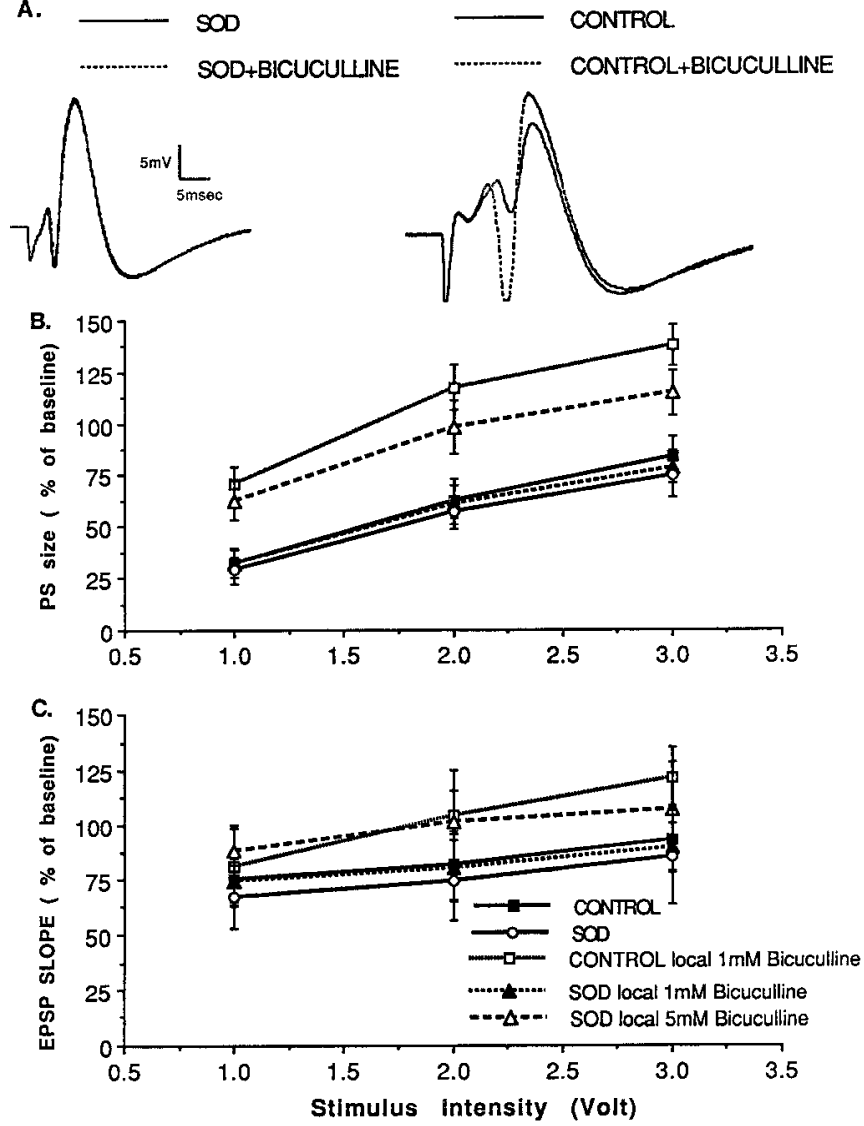

Figure 4. Differential effect of bicuculline in Tg-SOD and control mice. $A$, Sample illustration of population response to perforant path stimulation recorded with saline pipette and with 1 or $5 \mathrm{~mm}$ bicucullinecontaining pipettes. A large increase in population spike is seen in the control mouse, but not in the Tg-SOD mouse. $B$, $C$, Summary of inputoutput relations in the two groups of mice, in the different drug conditions. The control mice were not tested with $5 \mathrm{~mm}$ bicuculline, because most of them produced epileptic activity under these recording conditions. A clear increase in population spikes, on the background of small, if any, effect on population EPSPs, is seen.

\section{Patch recordings in brain slices}

Using infrared illumination, whole-cell patch-clamp recording was performed from neurons in the dentate granular layer in slices that were obtained from control and Tg-SOD mice. Recording was made from nongranular cells, presumably interneurons. The input resistance measured from the two populations of cells were similar in standard medium (control, $300.36 \pm 45.6$ $\mathrm{M} \Omega, n=11$; Tg-SOD, $269 \pm 29 \mathrm{M} \Omega, n=13$ ) and in TTXcontaining medium (control, $327 \pm 97, n=8$; Tg-SOD, $329 \pm 46$, $n=7)$.

The IPSPs appeared usually as single events (Fig. 6Aa, $A b$ ) in the control cells, but tended to cluster in the Tg-SOD cells. For example, clusters of more than five IPSCs grouped in $<100 \mathrm{msec}$ were never observed in control cells, whereas they were present in all of the Tg-SOD cells studied. Furthermore, the mean frequency of IPSCs in Tg-SOD was significantly higher than control: $14.4 \pm$ 2.08 and $8.46 \pm 1.06$, respectively (Fig. 6). The analysis of single event properties did not show any significant difference in other parameter such as amplitude, area, rise time, and decay time. The mean amplitude and the area evaluated do not represent properly the typical event because usually larger events appeared in clusters and were not included in the analysis of these parameters.
A.

CONTROL
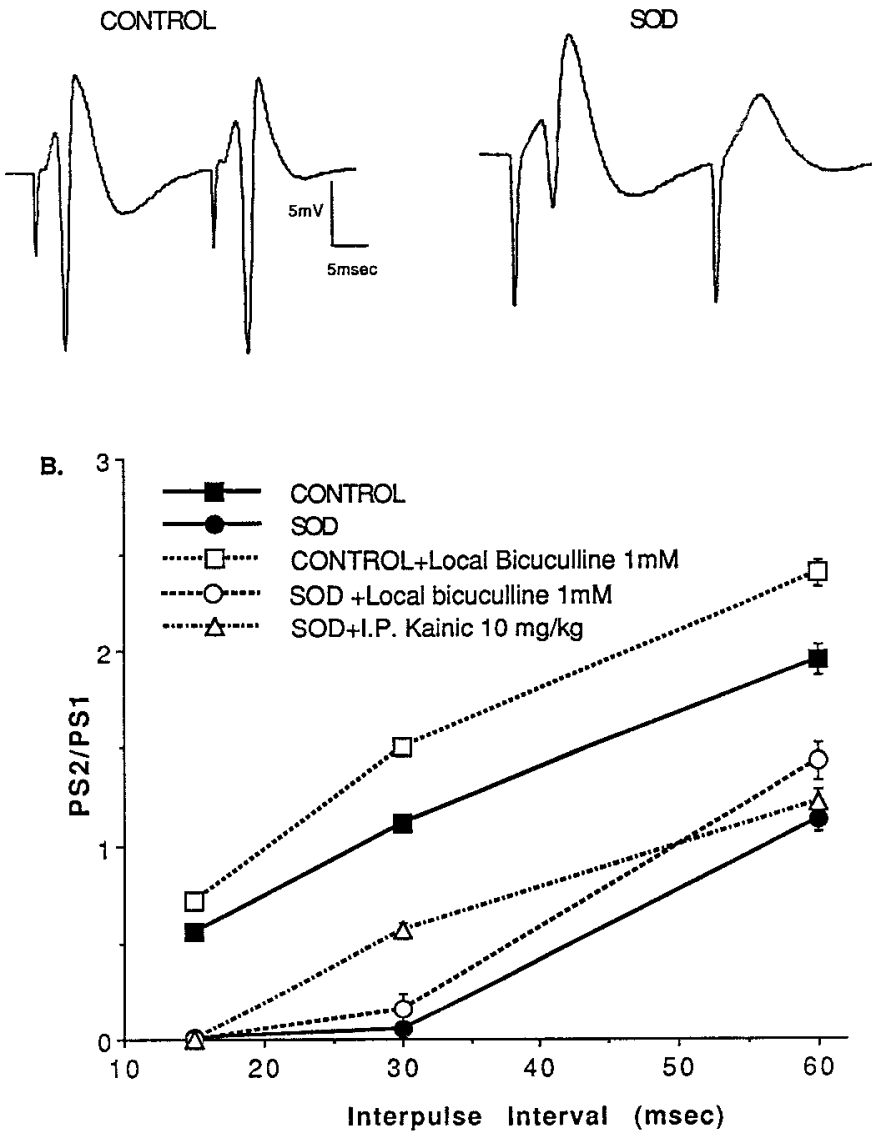

Figure 5. Paired-pulse depression is markedly enhanced in Tg-SOD mice. $A$, Illustrations of paired-pulse responses to stimulation applied with a $30 \mathrm{msec}$ interpulse interval in control and Tg-SOD mice. Note that the control mouse produced about the same size population spike to the two stimuli, whereas in the Tg-SOD mouse, the second population spike is totally eliminated. $B$, Summary of the paired-pulse responses in the two groups, using three interpulse intervals, while recording with saline pipette, with bicuculline-containing pipette, or in the KA-injected mice. Note the marked difference between the two groups already in control conditions, and the persistence of the effect also after blockade of inhibition.

These data suggest that in Tg-SOD cells there is an enhancement of GABAergic transmission. To examine further the properties of GABAergic synapses, mIPSPs were compared between Tg-SOD and controls perfused with TTX $(1 \mu \mathrm{M})$. Although even in the presence of TTX there were occasional clusters of events (two or three), the percentage of these events was similar in the two groups of cells. Moreover, no differences were found in frequency, amplitude, area, rise time, or decay time (Fig. 6B), suggesting that the action potential-independent GABA release is similar in the two groups of animals.

\section{Long-term potentiation in vivo}

The enhanced inhibition in the Tg-SOD mice associated with their reduced sensitivity to KA toxicity may also underlie their reduced ability to express long-term potentiation (LTP; Gahtan et al., 1998). We therefore studied LTP in the intact mouse after tetanic stimulation of the perforant path. In the control mice, tetanic stimulation produced LTP of both the EPSP slope and the population spike amplitude $(n=7$; PS $=60.85 \pm 13.7 \%$; EPSP $=$ $45.85 \pm 12.3 \%)$. In striking contrast, no LTP was produced in the Tg-SOD mice (Fig. 7). 


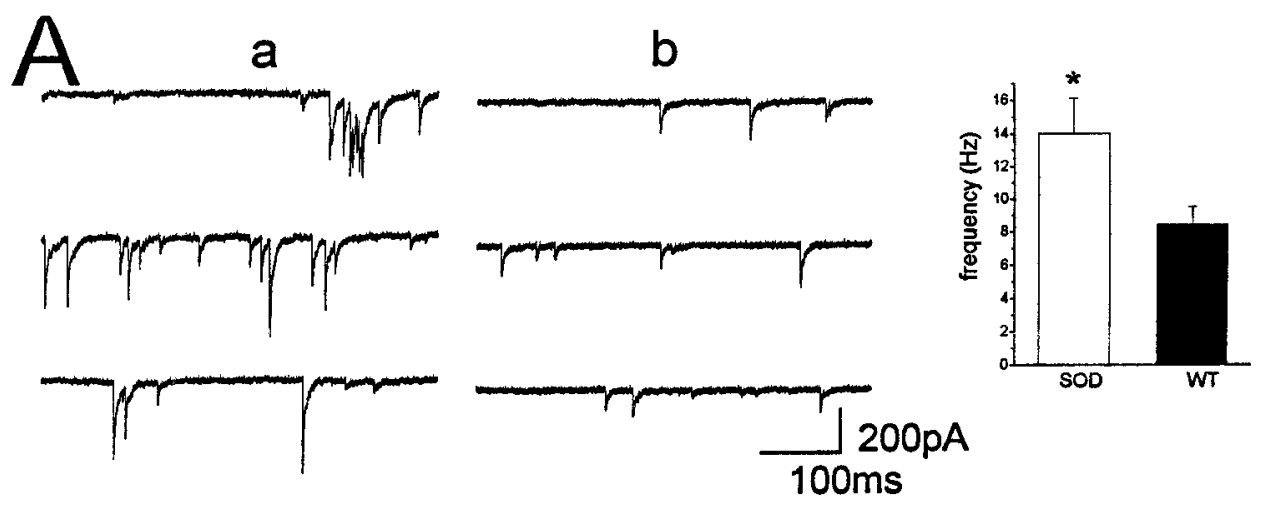

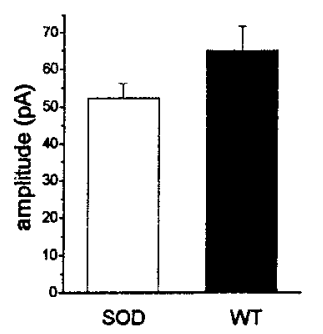

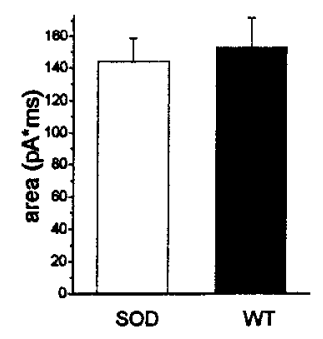

a
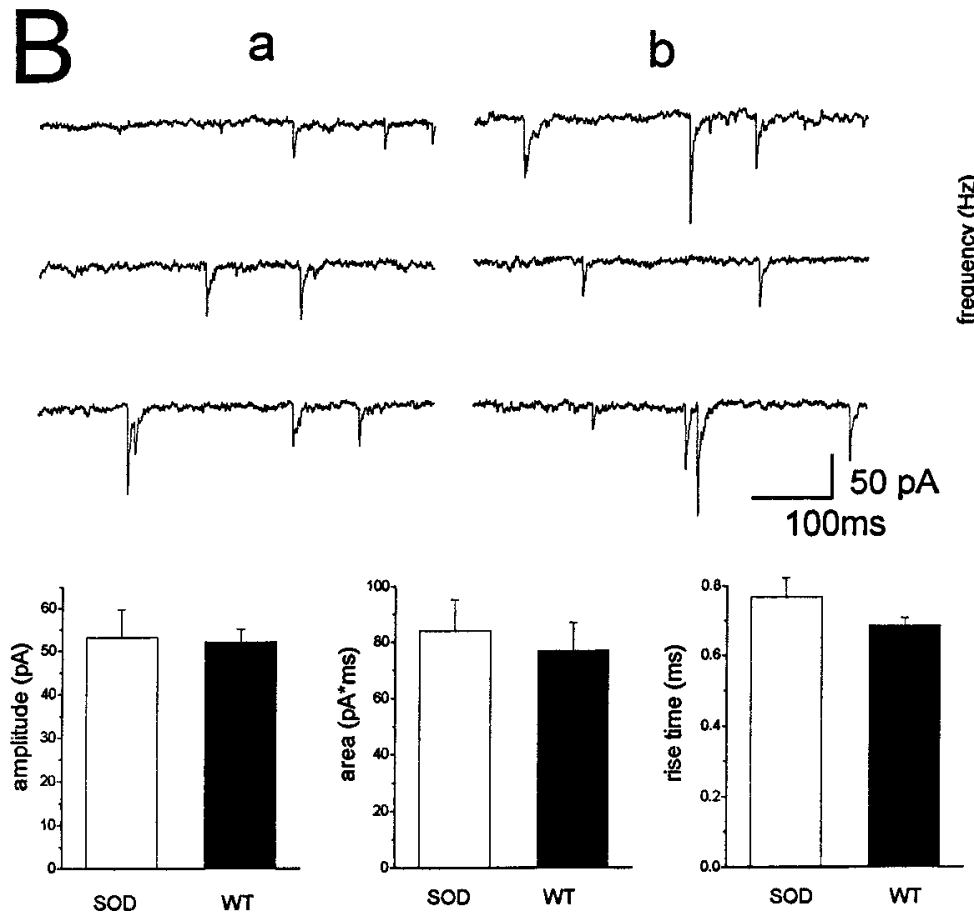

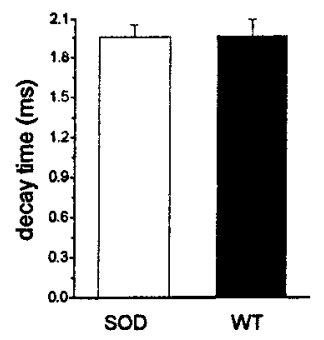

Figure 6. GABAergic action potentialdependent activity, but not mIPSPs, is enhanced in Tg-SOD mice. $A$, Examples of activity recorded in a slice obtained from a Tg-SOD mouse $(a)$ and control $(b)$. Traces are continuous recording from voltage-clamped cells in the presence of APV $(20 \mu \mathrm{M})$ and DNQX $(10 \mu \mathrm{M})$. In contrast to control, the activity recorded in Tg-SOD mice slices often appeared in clusters of many events. The histograms are the means of representative values of parameters measured in every cell $(n=6$ in each group). The mean frequency was significantly higher than that detected in control mice slices $\left({ }^{*} p=0.03\right)$, whereas the analysis of isolated events did not show any difference in amplitude, area, rise time, and decay time. $B$, Examples of miniature IPSP recorded in slices from $\mathrm{Tg}$-SOD mice $(a)$ and controls $(b)$. Cells were clamped at -65 $\mathrm{mV}$, and activity was recorded in the presence of TTX (1 mM), APV (20 $\mu \mathrm{M})$, and DNQX $(10 \mu \mathrm{M})$. In contrast to action potential-dependent activity, no difference was found in mIPSP frequency $(c)$, as in other parameters such as amplitude, area, rise time, and decay time.
To study if the inability to express LTP in the Tg-SOD mice is attributable to enhanced GABAergic inhibition, we blocked local inhibition with a recording pipette containing bicuculline (1 $\mathrm{mM})$. As seen before (Steward et al., 1990), this enabled LTP to be elicited in a dual pathway that does not produce LTP normally, and this was also the case in the Tg-SOD mice (Fig. 8) $(n=6$; $\mathrm{PS}=54.25 \pm 5.6 \%$; EPSP $=44.5 \pm 9.3 \%$ ).

The converse experiment was done with control mice. Inhibition can be enhanced by diazepam, and this treatment can abolish LTP formation in hippocampal slices (del Cerro et al., 1992). We injected diazepam (1 mg/kg, i.p), 15-20 min before tetanic stimulation. Diazepam abolished LTP production in control mice (Fig. 9) $(n=5$; control, PS $=60.85 \pm 13.6 \%$; EPSP $=42.42 \pm$
10.4\%; control + diazepam, PS $=8.75 \pm 4.78 \%$; EPSP $=3.25 \pm$ $8.84 \%$; $t$ test; $p<0.0007, p<0.0004$ for PS and EPSP, respectively). Increasing the dose of diazepam to $5 \mathrm{mg} / \mathrm{kg}$ not only inhibited LTP production but also induced paired-pulse inhibition in the 15 and $30 \mathrm{msec}$ interpulse intervals (Fig. 9) $(n=4$; control, IPI $=30$, PS2/PS1 $=1.11 \pm 0.19$; control + diazepam, $\mathrm{IPI}=30, \mathrm{PS} 2 / \mathrm{PS} 1=0 ; t$ test; $p<0.005)$. These experiments indicate that local GABAergic inhibition exerts a powerful control of the ability to express LTP.

\section{DISCUSSION}

The present experiments demonstrate that constitutive elevation of SOD-1 affects the excitability of local hippocampal circuits as 

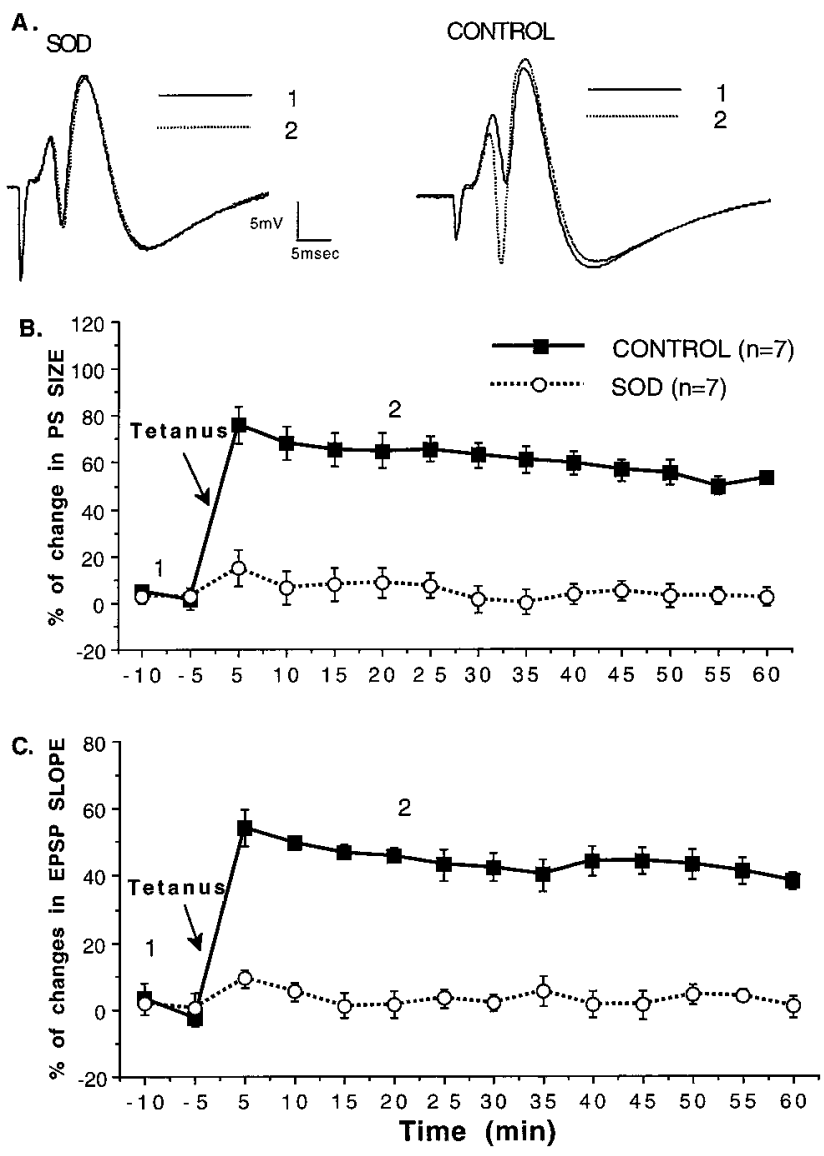

Figure 7. LTP is found in control but not Tg-SOD mice. $A$, Sample illustration of evoked responses before and after tetanic stimulation producing LTP in Tg-SOD and control mice. The numerals are taken at the time depicted in $B$ and $C$. Tetanic stimulation is applied at the arrow, and a clear difference between control and Tg-SOD mice is seen both with the population spike and the EPSP slopes.

well as the ability of the hippocampus to express LTP. This is reflected in the reduced susceptibility of the Tg-SOD mice to KA-induced epileptic seizure. Hippocampal neurons of Tg-SOD mice express higher rates of spontaneous inhibitory synaptic currents, which act to clamp the membrane potential near rest and prevent the depolarization needed to allow influx of calcium and subsequent synaptic plasticity. Even a mild blockade of this inhibitory tone with bicuculline restores the ability of the dentate gyrus of the Tg-SOD mice to express LTP, and conversely, enhancing the inhibitory tone in the control mice mimics the action of Tg-SOD in blocking the ability of the dentate gyrus to express LTP. These studies therefore link directly neuronal excitability with ability to express plasticity. The reduced ability to express LTP both in vivo and in the slice preparation (Gahtan et al., 1998) is correlated with the impaired performance of these mice in spatial memory tasks (Gahtan et al., 1998).

The physiological mechanism underlying the enhanced inhibition in the Tg-SOD mouse involves presynaptic GABAergic interneurons. The postsynaptic receptors seem to be the same in both control and Tg-SOD mice, in that the miniature inhibitory synaptic currents have the same magnitudes and decay time constants. The lack of differences in the latter property militates against a difference in reuptake of GABA in the presynaptic terminals. The main difference is that IPSCs in the
A.
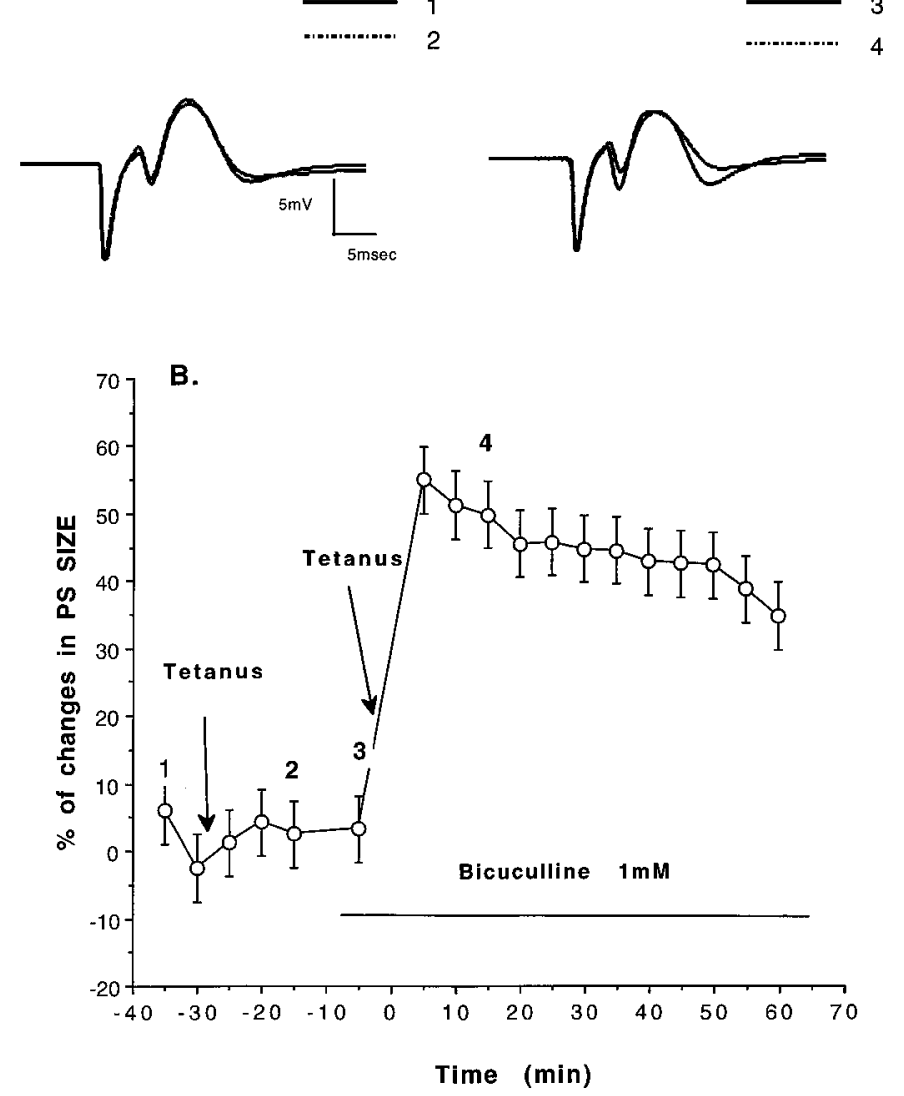

Figure 8. Bicuculline restored the ability to express LTP in Tg-SOD mice. Tetanic stimulation was first applied to the perforant path, and the response was recorded with a control pipette. Thereafter, the pipette was replaced with one containing $1 \mathrm{~mm}$ bicuculline, which by itself did not change the response characteristics of the hippocampus, but it did permit the expression of subsequent LTP to the same perforant path stimulation.

Tg-SOD mice tend to be more numerous and to cluster, indicating that either different inhibitory neurons fire in concert, or that single inhibitory neurons fire in bursts. Tentative evidence for the latter possibility has been seen in preliminary experiments where we found that interneurons in the dentate gyrus of the Tg-SOD mouse tend to fire in bursts (E. Avignone, unpublished observations).

The biochemical pathways leading to these functional differences between the brain of the Tg-SOD and controls mice are not entirely clear. It was previously shown that constitutive overexpression of SOD-1 lead to enhanced lipid peroxidation (ElroyStein et al., 1986; Elroy-Stein and Groner 1988; Avraham et al., 1988), which may cause the observed disruption of membrane pumps, including the serotonin transporter (Elroy-Stein and Groner, 1988). Serotonin has been implicated in the regulation of local inhibition in the hippocampus (Levkovitz and Segal, 1997). Thus, a constitutive downregulation of the serotonin transporter may have a long-term effect on modulation of local inhibition. This hypothesis awaits further examination. Still, SOD-1 may affect GABAergic neurotransmission directly, but the molecular events through which elevated SOD-1 may affect GABAergic interneurons selectively are not entirely understood. One major question is whether the effects of SOD-1 are constitutive or reactive, i.e., does the overexpression cause a constitutive change in GABAergic neurons, or is it only that tetanic stimulation or 

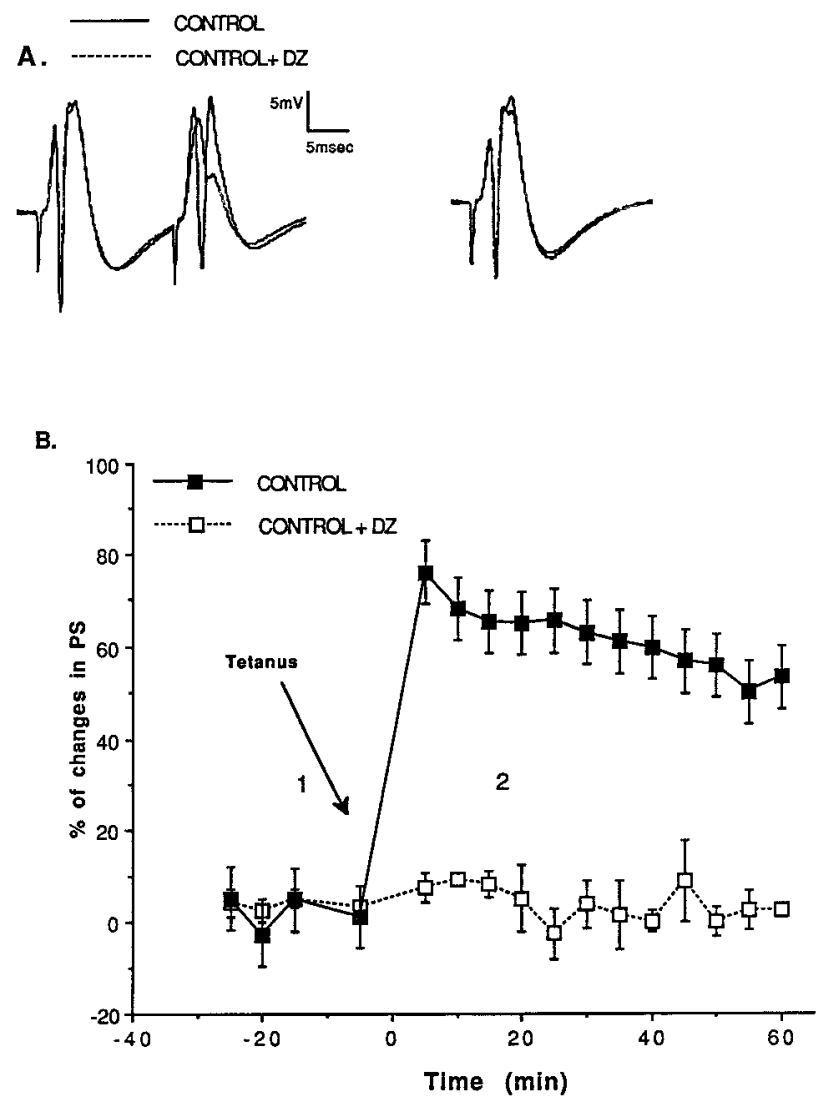

Figure 9. Diazepam ( $D Z$; intraperitoneal injection) blocks the ability of normal control mice to express LTP. Control and DZ-treated mice are shown, before and after tetanic stimulation applied to the perforant path. $A$, Paired-pulse depression is enhanced in control mice after injection of diazepam. $B$, Summary of the results with the tetanic stimulation in the two groups of control mice.

seizure cause enhanced formation of $\mathrm{H}_{2} \mathrm{O}_{2}$, which modifies GABAergic transmission acutely. The current results indicate that the former possibility is more likely, the response to a paired-pulse stimulation is already different between the two mice, and this is a very mild stimulation, not likely to cause such a large differential change in $\mathrm{H}_{2} \mathrm{O}_{2}$ production and subsequent change in inhibition. Thus, it is likely that the transgene produces a constitutive difference in functional inhibitory network in the hippocampus. Whether this is associated with a morphological change in specific GABAergic interneurons is yet to be determined. Likewise, whether the change in the GABAergic function is a primary or a secondary consequence of the $\mathrm{Tg}$-SOD is yet to be determined. The gross morphology of the hippocampus is not different between control and the Tg-SOD mouse, and there is no apparent difference in sensitivity of these mice to sensory stimulation (Gahtan et al., 1998), indicating that even if the effects of Tg-SOD are constitutive, they do not produce a major effect on brain morphology and connectivity.

There is an ongoing debate concerning the role of SOD-1 in neuroprotection versus neurosensitization. It has been suggested that overproduction of SOD-1 causes an increase in susceptibility to neurotoxic insults (Groner et al., 1994; Bar-Peled et al., 1996; Peled-Kamar et al., 1997), whereas others suggest that Tg-SOD-1 mice are more resistant to neurotoxicity (Chan et al., 1990; Merad-Saidoune et al., 1999). Our results do not address this issue directly. In the simple sense of the word, Tg-SOD mice are more protected against epileptic seizure caused by KA than matched controls. However, to compare neuroprotective efficacy against cell death, one needs to apply the amount of KA that will produce the same physiological response, e.g., seizure, in the transgenic and control mice and then compare cell death, which we obviously did not study here. Thus, a comparison of the final toxicity, without a comparison of physiological responses leading to the toxic results does not actually tell us if the neuroprotective mechanisms of the cell are impaired or that the physiological insult is actually different in the two cases.

Regardless of the biochemical mechanism affected by Tg-SOD, the current results place LTP, learning, and seizure on the same excitability dimension, in that the more excitable the tissue is, because of modulation of local GABAergic network, the higher the likelihood that it will produce long-term changes in synaptic strength. Phenomenologically, this effect is similar to that reported recently (Nosten-Bertrand et al., 1996; Hollrigel et al., 1998), it appears to share the same cellular but not necessarily the same molecular mechanisms. The single dimension that links excitability and plasticity is conceptually opposite to the scaling principle (Turrigiano, 1999), which predicts that a decrease in excitability will lead to an increase in ability to express LTP. This, however, may vary in different brain areas. At any rate, the Tg-SOD may provide a test system for examination of the role of local GABAergic circuits in regulation of plasticity.

\section{REFERENCES}

Amstad P, Peskin A, Shah G, Mirault ME, Moret R, Zbinden I, Cerutti P (1991) The balance between CuZn-superoxide dismutase and catalase affects the sensitivity of mouse epidermal cells to oxidative stress. Biochemistry 30:9305-9313.

Avraham KB, Schickler M, Sapoznikov D, Yarom R, Groner Y (1988) Down's syndrome: abnormal neuromuscular junction in tongue of transgenic mice with elevated levels of human $\mathrm{Cu} / \mathrm{Zn}$-superoxide dismutase. Cell 54:823-829.

Bar-Peled O, Korkotian E, Segal M, Groner Y (1996) Constitutive overexpression of $\mathrm{Cu} / \mathrm{Zn}$ superoxide dismutase exacerbates kainic acidinduced apoptosis of transgenic $\mathrm{Cu} / \mathrm{Zn}$ superoxide dismutase neurons. Proc Natl Acad Sci USA 93:8530-8535.

Ben-Ari Y (1985) Limbic seizure and brain damage produced by kainic acid: mechanisms and relevance to human temporal lobe epilepsy. Neuroscience 14:375-403.

Chan PH, Chu L, Chen SF, Carlson EJ, Epstein CJ (1990) Reduced neurotoxicity in transgenic mice overexpressing human copper-zincsuperoxide dismutase. Stroke 21:11180-11182.

Choi DW (1994) Calcium and excitotoxic neuron al injury. Ann NY Acad Sci 747:162-171.

del Cerro S, Jung M, Lynch G (1992) Benzodiazepines block long term potentiation in slices of hippocampus and piriform cortex. Neuroscience 49:1-6.

Elroy-Stein O, Groner Y (1988) Impaired neurotransmitter uptake in rat PC12 cells overexpressing human $\mathrm{Cu} / \mathrm{Zn}$-superoxide dismutase. Implication for gene dosage effects in Down's syndrome. Cell 52:259-267.

Elroy-Stein O, Bernstein Y, Groner Y (1986) Overproduction of human $\mathrm{Cu} / \mathrm{Zn}$ - superoxide dismutase in transfected cells: extenuation of paraquat-mediated cytotoxicity and enhancement of lipid peroxidation. EMBO J 5:616-622.

Epstein CJ, Avraham KB, Lovett M, Smith S, Elroy-Stein O, Rotman G, Bry C, Groner Y (1987) Transgenic mice with increased $\mathrm{Cu} / \mathrm{Zn}$ superoxide dismutase activity: animal model of dosage effects in Down's syndrome. Proc Natl Acad Sci USA 1987 84:8044-8048.

Gahtan E, Auerbach JM, Groner Y, Segal M (1998) Reversible impairment of ong Term Potentiation in Transgenic $\mathrm{Cu} / \mathrm{Zn}-\mathrm{SOD}$ mice. Eur J Neurosci 10:538-544.

Groner Y, Elroy-Stein O, Avraham KB, Schickler M, Knobler H, MincGolomb D, Bar-Peled O, Yarom R, Rotshenker S (1994) Cell damage by excess CuZnSOD and Down's syndrome. Biomed Pharmacother 48:231-240. 
Halliwell B (1992) Reactive oxygen species and the central nervous system. J. Neurochem 59:1609-1623.

Hollrigel GS, Morris RJ, Soltesz I (1998) Enhanced bursts of IPSCs in dentate granular cells in mice with regionally inhibited long term potentiation. Proc R Soc Lond B Biol Sci 265:63-69.

Kondo T, Sharp FR, Honkaniemi J, Mikawa S, Epstein CJ, Chan PH (1997) , DNA fragmentation and prolonged expression of c-Fos, c-jun and hsp70 in kainic acid-induced neuronal cell death in transgenic mice overexpressing human $\mathrm{CuZn}$-superoxide dismutase. J Cereb Blood Flow Metab 17:241-256.

Levkovitz Y, Segal M (1997) Serotonin 5-HT1A receptors modulate hippocampal reactivity to afferent stimulation. J Neurosci 17:5591-5598.

Merad-Saidoune M, Boitier E, Nicole A, Marsac C, Martinou JC, Sola B, Sinet MP, Ceballos-Picot I (1999) Overproduction of $\mathrm{Cu} / \mathrm{Zn}$ superoxide dismutase or Bcl-2 prevents the brain mitochondrial respiratory dysfunction induced by glutathione depletion. Exp Neurol 158: $428-436$.

Nosten-Bertrand M, Errington ML, Murphy KP, Tokugawa Y, Barboni E, Kozlova E, Michalovich D, Morris RG, Silver J, Stewart CL, Bliss TV, Morris RJ (1996) Normal spatial learning despite regional inhibition of LTP in mice lacking Thy-1. Nature 379:826-829.
Norris HK, Hornsby PJ (1990) Cytotoxic effects of expression of human superoxide dismutase in bovine adrenocortical cells. Mutat Res 237:95-106.

Peled-Kamar M, Lotem J, Wirguin I, Weiner L, Hermalin A, Groner Y (1997) Oxidative stress mediates impairment of muscle function in transgenic mice with elevated level of wild-type $\mathrm{Cu} / \mathrm{Zn}$ superoxide dismutase. Proc Natl Acad Sci USA 94:3883-3887.

Sloviter RS (1991) Feedforward and feedback inhibition of hippocampal principal cell activity evoked by perforant path stimulation: GABAmediated mechanisms that regulate excitability in vivo. Hippocampus 1:31-40.

Steward O, Tomasulo R, Levy WB (1990) Blockade of inhibition in a pathway with dual excitatory and inhibitory action unmasks a capability for LTP that is otherwise not expressed. Brain Res 516:292-300.

Turrigiano GG (1999) Homeostatic plasticity in neuronal networks: the more things change, the more they stay the same. Trends Neurosci 22:221-227.

Yang DD, Kuan CY, Whitmarsh AJ, Rincn M, Zheng TS, Davis RJ, Rakic P, Flavell RA (1997) Absence of excitotoxicity-induced apoptosis in the hippocampus of mice lacking the Jnk3 gene. Nature 389:865870 . 